\title{
MEDICATION SYSTEM: ANALYSIS OF ACTIONS TAKEN BY PROFESSIONALS IN PSYCHIATRIC UNITS
}

\author{
Maristela Monteschi Souta1, Paulo Celso Prado Telles Filho², Kelly Graziani Giacchero Vedana³, Luiz Jorge \\ Pedrão ${ }^{4}$, Adriana Inocenti Miasso ${ }^{5}$
}

${ }^{1}$ PhD in Sciences. Ribeirão Preto, São Paulo, Brazil. E-mail: maristelamonteschi@yahoo.com.br
2 PhD in Nursing. Professor, Universidade Federal dos Vales do Jequitinhonha e Mucuri. Teófilo Otoni, Minas Gerais, Brazil. E-mail:
ppradotelles@outlook.com
${ }^{3}$ PhD in Nursing. Professor, Psychiatric Nursing Department, Escola de Enfermagem de Riberão Preto (EERP), Universidade de São
Paulo (USP). Ribeirão Preto, São Paulo, Brazil. E-mail: kellygiachero@eerp.usp.br
${ }^{4}$ PhD in Nursing. Professor, Psychiatric Nursing Department, EERP/USP. Ribeirão Preto, São Paulo, Brazil. E-mail: lujope@eerp.
usp.br
${ }^{5}$ PhD in Nursing. Professor, Psychiatric Nursing Department, EERP/USP. Ribeirão Preto, São Paulo, Brazil. E-mail: amiasso@
hotmail.com

ABSTRACT: This study analyzed the medication systems in psychiatric units of a general hospital and a psychiatric hospital in the state of São Paulo, Brazil. It is a quantitative and cross-sectional, exploratory survey study with 144 professionals from the areas of medication, nursing and pharmacy. Data were collected by direct, non-participative observation and by medical records review. Data were analyzed using descriptive statistics. Factors that affect patient safety, such as interruptions during prescription, handwritten changes to electronic prescriptions, limited handling of the electronic prescription system, unavailable clinical pharmacy, mistakes in activities related to the preparation and administration of medications and other factors were identified. The study reveals the susceptible points for the occurrence of medication errors in psychiatric hospitalization departments and discusses recommendations and technological resources that can promote security in the medication system.

DESCRITORS: Medication errors. Safety management. Medication system. Mental health.

\section{SISTEMA DE MEDICAÇÃO: ANÁLISE DAS AÇÕES DOS PROFISSIONAIS EM UNIDADES DE INTERNAÇÃO PSIQUIÁTRICA}

RESUMO: Este estudo analisou os sistemas de medicação em unidades de psiquiatria de um hospital geral e de um hospital psiquiátrico, do interior de São Paulo, Brasil. Trata-se de estudo quantitativo, transversal, tipo survey exploratório e realizado com 144 profissionais da medicina, enfermagem e farmácia. Os dados foram coletados por observação não participante direta e revisão em prontuários e foram analisados por estatística descritiva. Foram identificados fatores que desfavorecem a segurança do paciente como interrupções, durante a atividade de prescrição, alterações manuscritas em prescrições eletrônicas, restrições no manuseio do sistema eletrônico de prescrição, indisponibilidade de farmácia clínica, falhas nas atividades relacionadas ao preparo e à administração dos medicamentos e outros. Este estudo revela pontos vulneráveis para a ocorrência de erros de medicação em serviços de internação psiquiátrica e discute recomendações e recursos tecnológicos que podem promover a segurança no sistema de medicação.

DESCRITORES: Erros de medicação. Gerenciamento de segurança. Sistema de medicação. Saúde mental.

\section{SISTEMA DE MEDICACÍON: ANÁLISIS DE LAS ACCIONES PROFESIONALES EN UNIDADES PSIQUIÁTRICAS}

RESUMEN: Este estudio analizó los sistemas de medicación en unidades psiquiátricas de un hospital general y de un hospital psiquiátrico del interior del estado de Sao Paulo, en Brasil. Estudio cuantitativo, transversal y exploratorio. Participaron de la encuesta 144 profesionales de medicina, enfermería y farmacia. Los datos fueron obtenidos por medio de observación no participante directa y revisión de fichas médicas y se analizaron por estadística descriptiva. Fueron identificados factores que no favorecen la seguridad del paciente como: interrupciones durante la actividad de prescripción; modificaciones escritas en prescripciones electrónicas; restricciones en la manipulación del sistema electrónico de prescripción, indisponibilidad farmacéutica; fallas en las actividades relacionadas en la preparación y administración de los medicamentos, y otros factores. Este estudio revela puntos vulnerables para casos de errores de medicación en servicios de internación psiquiátrica y discute recomendaciones y recursos tecnológicos que pueden promover la seguridad en el sistema de medicación.

DESCRIPTORES: Errores de medicación. Administración de seguridad. Sistema de medicación. Salud mental. 


\section{INTRODUCTION}

The medication system in hospital institutions is complex, and involves consecutive actions of different health professionals. This can lead to the occurrence of medication errors ${ }^{1}$ at different stages, such as prescription, dispensation, preparation and administration.

Nowadays, medication errors are brought to light because they affect the quality of patient care and contribute to increase morbidity, mortality, length of hospital stay and financial health costs. ${ }^{2-4}$

There is a shortage of studies on medication errors in psychiatry, especially in comparison with other health areas. ${ }^{5}$ However, a study conducted in the United Kingdom observed that medication errors are common in mental health services, and that $56.2 \%$ of the errors occurred in patients hospitalized in wards, during three months of hospitalization. ${ }^{6}$ Another study of medication errors in a Japanese psychiatric hospital found a 2.14 rate of medication errors reported for every 1,000 patients per day, which suggests the underreporting of medication errors in the studied context. ${ }^{7}$ The focus of assistance should therefore be on strategies that prevent errors at different stages of the medication system and ensure patient safety. Among these strategies, a systemic approach to medication error, which considers failures in the medication system processes and not errors incurred by professionals involved stands out. Thus, the strategy is to prevent errors instead of finding a culprit. ${ }^{8}$

Internationally, error-related data in medication administration are alarming; since nurses are highly involved in this process, they are co-responsible for the good flow of the medication system. Consequently, nursing is fundamental for the reduction and prevention of medication errors. ${ }^{1,9-10}$ Nurses must play an active role in identifying, reporting and analyzing errors in the medication system. Furthermore, their role is essential for monitoring, planning interventions and policies to promote safety, medication administration and maximize benefits of patient-related care. ${ }^{3}$

This study is relevant because it is an opportunity to show susceptible issues for on the occurrence of medication errors at the different stages of the medication system in psychiatric units and, to provide support in implementing practical actions that can lead to an effective change to the current medication systems. Within this context, this study was aimed at analyzing the medication prescription, dispensation, preparation and administrations processes in psychiatric units of a general hospital $(\mathrm{GH})$ and a psychiatric hospital $(\mathrm{PH})$, both in the state of São Paulo, Brazil.

\section{METHOD}

This is a quantitative, cross-sectional exploratory survey study. It was performed in two psychiatric units of a public GH and four psychiatric units for acute patients care of a public PH, in 2012 and during the first semester of 2013. The psychiatric units of the general hospital had a total of 24 beds, 15 in unit A and 9 in unit B. In the psychiatric hospital, the following were investigated: unit C as "first admission" (17 beds), unit D as "psychosocial care" (15 beds), unit E as "acute male" (13 beds) and unit F "acute female" (13 beds), totaling 58 beds.

The sample in both hospitals consisted of all the professionals who met the inclusion criteria: staff of the units under study in charge of functions related to the medication of hospitalized patients. Professionals who were off duty or on vacation during the data collection period were excluded.

The study population was composed of all professionals of the medical (13), nursing (99) and pharmaceutical (54) teams of the investigated units. Thirteen professionals refused to participate in the study, and nine were absent. Therefore, the sample included 12 doctors, 17 nurses, 65 nursing assistants and/or technicians, 13 pharmacists and 37 pharmacy assistants, totaling 144 professionals.

A trained researcher made direct and nonparticipative observations for data collection in the hospitalization units and in hospital pharmacies. The observations focused on the medication prescription, dispensation, preparation and administration performed by these professionals. During data collection, when more than one professional was involved in the activity only the first healthcare professional to start the activity was observed.

Each process was observed for a week in each unit, divided into three morning shifts, two afternoon shifts and two night shifts. The number of morning shifts was justified by the higher flow 
of medications in this period. The observation followed an adapted a structured script, ${ }^{11}$ which was used to collect data from prescriptions. ${ }^{12}$.The data were analyzed using descriptive statistics and presented in tables, with absolute and relative frequencies.

The study was approved by the Research Ethics Committee (Process HCRP No. 6911/2010). Participants signed an Informed Consent Form for Participation in Research, in accordance with Resolution N. 196/96.

\section{RESULTS}

The medication system, in both hospitals, involved several steps and different professional categories. Some differences were identified when the study sites' flowcharts were compared. In the dispensation process, services differed as to the professionals who participated in the process, the containers in which the patients' medications were placed, and in the drug transportation and distribution to the units. Clerks and messengers participated in the dispensation at the $\mathrm{GH}$, as opposed to the $\mathrm{PH}$, where the pharmacy assistants were predominantly in charge.

Messengers were responsible for medication distribution at the inpatient units at the $\mathrm{GH}$, while, nursing professionals collected medications from the Pharmacy and took them to the sectors at the PH. The messengers' distribution system reduced the nursing staff's activity load and allowed for faster medication delivery, since delivery was the messenger's single task.

It was observed that nursing professionals at the GH checked the dispensed medications when they received them and when they separated them for the patients. At the $\mathrm{PH}$, nursing professionals only checked each patient's drugs at the time of separating them in the unit.

A flowchart of the hospitals, showing general aspects of the medication prescription, dispensation, preparation and administration processes is presented below.

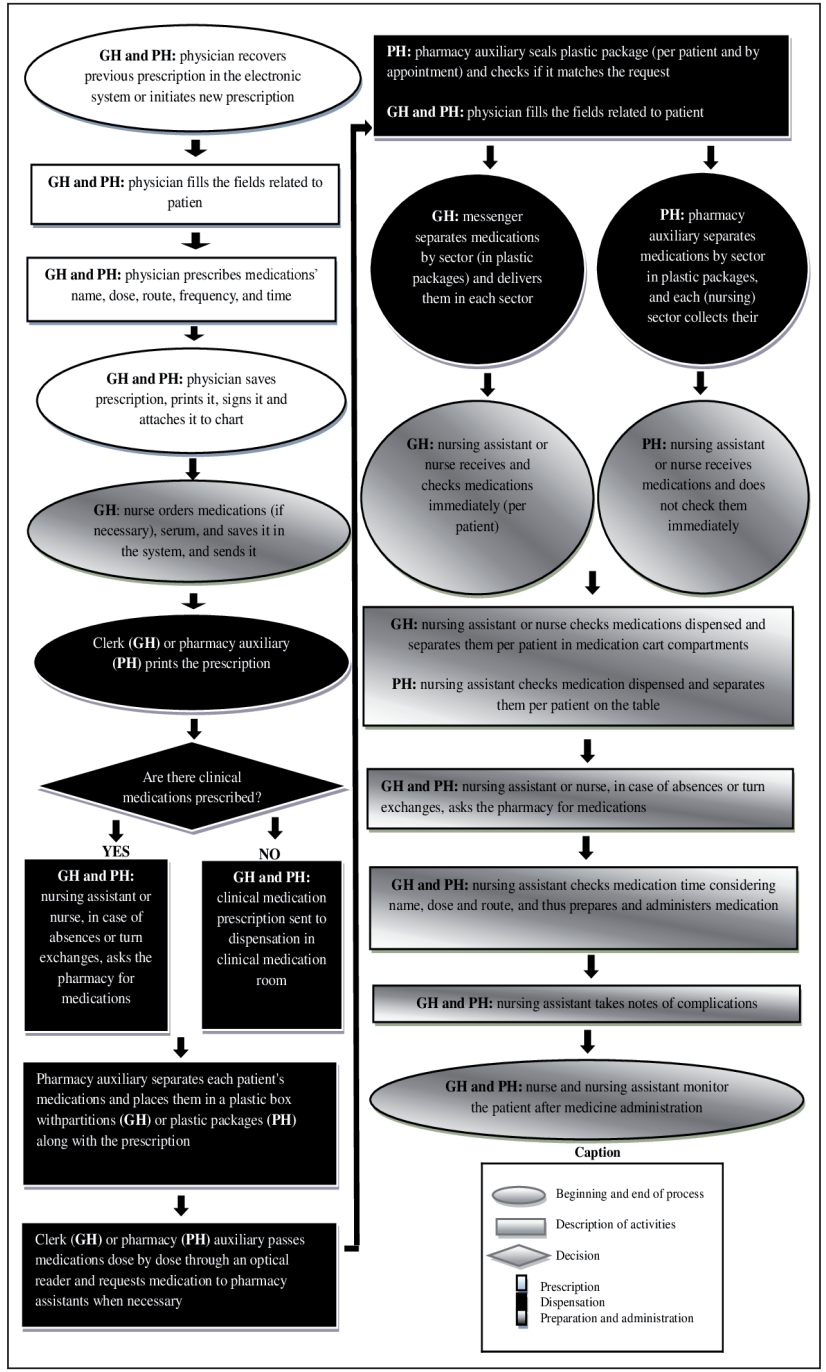

Figure 1- General Hospital (GH) and Psychiatric Hospital (PH) comparative flowchart

The steps in the medication system are presented below.

\section{Medication prescription process}

At the $\mathrm{GH}$, unit $\mathrm{A}$ had an exclusive place for medical prescription, and unit B was often shared with other professionals. In the four investigated units of the $\mathrm{PH}$, there were exclusive places for medical prescription: locked medical offices. Prescriptions were not always issued in the areas designated for this activity. 
In all studied units, low volume radio and fans were on at the time of prescription. In addition, the team, patients, phones and conversations near the person doing the prescription caused interruptions.

In both hospitals, the medical prescription was electronic, but it was observed that handwritten changes were made after the initial prescription.

At the $\mathrm{PH}$, electronic system operation was compromised by the difficulties the professionals had in handling the system, and by occasional technical issues, such as blocking the checking of some medications and medical prescription duplication.
In both hospitals, it was observed that prescriptions were issued without medical assessment during the shift. At the $\mathrm{GH}$, prescriptions were issued daily, while at the $\mathrm{PH}$, they were valid for approximately ten days.

Table 1 shows the distribution of problems identified in the prescriptions. At the GH, 114 medical prescriptions were analyzed in unit $A$ and 55 in unit $\mathrm{B}$, totaling 169 prescriptions. At the $\mathrm{PH}, 109$ prescriptions were analyzed, out of which 37 were from unit C, 31 from unit D, 18 from unit $\mathrm{E}$ and 23 and from unit $\mathrm{F}$.

Table 1- Distribution of problems identified in prescriptions from a General Hospital and a Psychiatric Hospital. Ribeirão Preto-SP, Brazil, 2013

\begin{tabular}{|c|c|c|c|c|}
\hline \multirow[t]{2}{*}{ Variables } & \multicolumn{2}{|c|}{$\begin{array}{c}\text { General hospital } \\
n=169\end{array}$} & \multicolumn{2}{|c|}{$\begin{array}{l}\text { Psychiatric hospital } \\
n=109\end{array}$} \\
\hline & $\mathbf{n}$ & $\%$ & n & $\%$ \\
\hline Duplicated medication prescription & - & - & 03 & 2,7 \\
\hline Route of administration error & - & - & 01 & 0,9 \\
\hline Out of stock medication & 01 & 0,6 & - & - \\
\hline Handwritten change: item suspension & 16 & 9,5 & 02 & 1,8 \\
\hline Handwritten change: dose alteration & 06 & 3,5 & 01 & 0,9 \\
\hline Handwritten change: schedule alteration & 05 & 2,9 & - & - \\
\hline Handwritten change: medication addition & 06 & 3,5 & - & - \\
\hline
\end{tabular}

At the $\mathrm{GH}, 19.4 \%$ of prescriptions were changed by hand, while only $2.7 \%$ at the $\mathrm{PH}$. At the $\mathrm{PH}$, duplicated prescriptions $(2.7 \%)$ and an error in the route of administration of the prescribed medication $(0.9 \%)$ occurred. The duplicated items on prescriptions were related to such medications as dipyrone sodium and mucilloid; in a single prescription, there was duplication of biperiden, haloperidol and sertraline.

Regarding the medication prescribed with an inadequate route of administration, dipyrone was prescribed for nasal use, due to a selection error in the electronic system. The route of administration was not corrected in the electronic system or by the prescriber.

With regard to handwritten changes, a change in an antibiotic schedule was highlighted. The medication had been prescribed for Monday, Wednesday and Friday, and the doctor changed it manually for Tuesday, Thursday and Saturday. Such conduct generates potential errors, since the pharmacy dispenses antibiotics according to the original electronic prescription.

\section{Medication dispensation process}

The dispensing pharmacies at the GH and the $\mathrm{PH}$ medications for the investigated units have common characteristics. Both followed the regulations of Ordinance SVS/MS No. 344/98, ${ }^{13}$ were open 24 hours a day and had a higher number of dispensations in the morning. The medications were arranged in alphabetical order and sorted by active ingredient name. In both institutions, pharmacy assistants performed the reposition and the validity and integrity control.

Clinical and psychiatric medications were stored in separate stocks in the two hospitals. At the $\mathrm{GH}$, controlled medications were locked, as opposed to the $\mathrm{PH}$. The pharmacy assistants responsible for the psychotropic room in the GH did not rotate for greater control of psychotropic drug dispensation. In both hospitals, each drug was read by the optical reader, and the electronic system indicated errors through a message of the duplicity or lack of items. The dispensation system was electronic, in individual doses and guided by the generic medication name in the electronic prescriptions. 
Pharmacists did not systematically review the pharmacy prescriptions under investigation. There were not enough pharmacists to assist in the wards, and clarifications were provided over the phone.

Wards at the GH had a small supply of medications such as analgesics, large volume solutions, emergency medication and psychotropic drugs. The mini psychotropic stock was dispensed, in accordance with Decree N. 344/98, ${ }^{13}$ and restored upon medical prescription, after medication use.

At the $\mathrm{PH}$, errors were observed in the separation of medications, including a greater or smaller dosage than prescribed, and changed medications. However, incorrect doses were not dispensed because all errors in medication separation were blocked by the electronic system. Manual registration of dispensed medications was observed in some situations. When the system requested information, the pharmacy assistants continued the registration without checking the medication and information beforehand. Another problem was changing the medication after electronic system registration and before the sealing process.

\section{Medication preparation and administration process}

There were sinks for hand washing and a storage room for medication in the places designated for medication preparation. These places were occasionally unlocked, which can contribute towards inadequate medication use.

Situations in which medication packages were opened during preparation were registered. This can lead to tablet exchange, as they are no longer identifiable. At the $\mathrm{PH}$, medications were administered in front of the nurses' station, and patients crowded while they waited for their medication.

Table 2 shows the distribution of nursing technicians or assistants' actions. All actions were observed for each patient during a week: some patients were observed more than once, on different days, and each observation was counted. This justifies the totals of 95 and 135 patients in the $\mathrm{GH}$ and the $\mathrm{PH}$, respectively.

Table 2 - Distribution of nursing technicians' or assistants' actions in the patient medication preparation and administration stage at the General Hospital and the Psychiatric Hospital. Ribeirão Preto-SP, Brazil, 2013

\begin{tabular}{lcccc}
\hline Observed actions & \multicolumn{3}{c}{$\begin{array}{c}\text { General Hospital } \\
\text { n }\end{array}$} & \multicolumn{2}{c}{$\begin{array}{c}\text { Psychiatric Hospital } \\
\mathbf{n}=\mathbf{1 3 5}\end{array}$} \\
& $\mathbf{n}$ & $\mathbf{9}$ & $\mathbf{n}$ & $\mathbf{\%}$ \\
\hline Hand hygiene & 63 & 66,3 & 84 & 62,2 \\
Interruptions during the process & 25 & 26,3 & 50 & 37,0 \\
Check vital signs together with medication administration & 80 & 84,2 & 127 & 94,1 \\
Check the medication and the medical prescription & 95 & 100 & 129 & 95,5 \\
Present medication to patient in identified package & 91 & 95,8 & 116 & 85,9 \\
Leave medication exposed without supervision & 13 & 13,6 & 25 & 18,5 \\
Leave psychotropic substances stored unlocked & 35 & 36,8 & 13 & 9,6 \\
Administer medication on time or up to 30 minutes early or late & 86 & 90,5 & 112 & 82,9 \\
Take medical prescription to the patient & 70 & 73,6 & - & - \\
Check patient by name and bed & 62 & 65,2 & 90 & 66,6 \\
Instruct patient about medication & 07 & 7,3 & 10 & 7,4 \\
Confirm medication intake & 86 & 90,5 & 84 & 62,2 \\
Check prescription immediately after administration & 57 & 60 & 50 & 37,0 \\
Monitor patient & 25 & 26,3 & 13 & 9,6 \\
\hline
\end{tabular}

In table 2, it can be seen that only the medication and medical prescription check was performed for all patients, only at the GH. Errors were recorded in all other actions in both hospitals, and potential mistakes were observed at this stage of the medication system as well. Hand hy- giene was not performed in $33.7 \%$ of procedures at the $\mathrm{GH}$, and $37.8 \%$ at the PH. Moreover, it was observed that some professionals consecutively administered medications to several patients and only performed hand hygiene before the first administration. 
No nursing professional took the prescription to the patient when administering the medication at the PH. All professionals prepared the medication in advance and did not check the prescription with the patient. Such action was done with $73.6 \%$ of the patients at the GH. There were mistakes in checking the patient by name and bed. A minority of patients was instructed when receiving the medication $(7.3 \%$ at the $\mathrm{GH}$ and $7.4 \%$ at the $\mathrm{PH}$ ) - this was the least performed action in medication administration.

Confirmation of drug intake was for only for $62.2 \%$ of patients at the $\mathrm{PH}$, and for $90.5 \%$ at the GH. A minority of patients was monitored after medication administration $(26.3 \%$ at the HG and $9.6 \%$ at the $\mathrm{PH}$ ). The participation of nurses was not observed in medication preparation and administration medications in either hospital.

Regarding proposal for improvement to the medication system, an information center was being implemented at the $\mathrm{GH}$, including medication manuals for electronic access designed by a multidisciplinary team. Some sectors (which did not include psychiatry) had a clinical pharmacy and pharmacovigilance-related actions. The implementation of a unit dose medication system and bedside technology use had been planned. The GH had proposals to improve the medication system and to develop a pharmacovigilance program.

\section{DISCUSSION}

The medication system flowchart for both hospitals reveals differences that can affect the system's safety and operation. Electronic medical prescription indicated an effort to prevent medication errors - the use of technology to computerize medical prescriptions can prevent errors related to writing or reading the handwritten prescription. ${ }^{2}$

The professionals had difficulties to use the electronic prescription properly and handwritten changes occurred after the initial prescription. Exclusive electronic medication prescription is indicated as an important strategy to prevent errors and problems arising from the poor understanding of prescription. ${ }^{14}$ To prevent medication errors, it is recommended is to make all changes electronically and immediately inform the entire team. The medical prescription should be systematically consulted during medication preparation and administration.

The Brazilian Common Denomination (Denominação Comum Brasileira, DCB) states that the prescription should be legible and include the dosage, route of administration, concentration, prescription date, duration of treatment, amount of medication, patient identification, pharmaceutical form and the physician's seal with his/her Regional Medical Board registration number. ${ }^{15}$ The electronic prescription includes mandatory fields that ensure this information is registered.

There was noise and disruption in the environment where the prescription was issued, which can interfere with patient safety and contribute towards mistakes in the prescription process. Organizational strategies are necessary in order to lessen them. ${ }^{16}$

Duplicated prescriptions were observed at the $\mathrm{PH}$, which can contribute towards the dispensation and administration of duplicated items and therefore, constitute potential medication error. Such aspect is alarming as psychiatric drugs, often prescribed in psychiatric units, present high risk of toxicity and may expose patients to poisoning, when administered in double doses.

The department of nursing intercepted the error in the medication prescribed with the inadequate route of administration. It should be noted that routes for which there is no application of a medication should be blocked in the electronic system for patient safety. The literature shows that when the nursing staff has knowledge of the medications, it becomes an important barrier for medication errors. ${ }^{17}$

In one of the investigated hospitals, the difficulty professionals had to operate the electronic system was evident. It is important to highlight that the technological training of professionals is highly recommended for the implementation of the electronic system as a tool for patient safety and error prevention. ${ }^{14}$

The individualized dose dispensation system in both hospitals allows for the review of medical prescriptions, greater control over medication stock and stock reduction in units. However, the unit dose system is a more advanced and secure alternative that does not require nursing manipulation, since the medication is available in the exact dose needed for each patient, for up to 24 hours. ${ }^{18}$

There was no clinical pharmacist in the investigated pharmacies and the prescriptions were not reviewed. In this respect, the literature indicates a medical acceptance rate of $47 \%$ regarding pharmaceutical interventions and information on prescriptions. ${ }^{19}$ In accordance with Ordinance GM/ MS 4283/2010, ${ }^{20}$ prescription review and analysis 
of prescriptions by a pharmacist is mandatory, and must prioritize potentially dangerous or high surveillance medication. The use of an electronic program is highly recommended for pharmaceutical support in the process of prescription analysis. Therefore, the pharmacist must observe the concentration, viability, physical-chemical and pharmacological compatibility of the components, dosage, pharmaceutical form, route of administration and time of administration. ${ }^{21}$ Furthermore, investments in the clinical pharmacist's performance can generate direct benefits to patient safety and maximize the quality of care. ${ }^{22}$

Regarding the medication preparation and administration procedure - a stage of the nursing staff's competence system - the observed failures are potential for medication errors. Medication administration represents the last chance of checking and preventing errors, which is fundamental to reduce preventable harm to the patient. ${ }^{1,9}$ However, a study in psychiatric wards in Denmark identified that the majority $(75 \%)$ of medication errors that occurred were related to the medication administration step. ${ }^{9}$

The lack of hand hygiene was observed in most procedures. The literature shows that hands must be sanitized each time the nursing staff offers care, including medications, to prevent infection. ${ }^{23}$

Mistakes related to checking the patient's name and bed were observed in both hospitals. Patient identification during the medication preparation and administration process is the premise to prevent mistakes that lead to patient changes. According to the literature, the patients must be asked their full name before the medication is administered. In addition, the use of at least two identifiers to confirm the correct patient is necessary, such as the name in the patient's bracelet, bed and chart. ${ }^{21}$

Surprisingly, patient instruction at the time of drug administration was one of the actions the nursing professionals least performed actions. Failures to confirm medication intake were also observed. Knowledge of the drug treatment is relevant for the patient to intercept errors at the time the medication is administered. Thus, guidance on medications and confirmation of intake are particularly important among people with mental disorders, because treatment compliance in this patient group is a major challenge to clinical practice. ${ }^{24}$

The patient must always be monitored after medication administration. In this study, however, such action was performed for the minority of patients. In monitoring, the professional needs to maintain a clear communication with the patient, to consider the patient's and/or his/her caregiver's observations and reports on the effects of the administered drugs, and to register all the monitoring parameters. ${ }^{21}$

In this study, interruptions in medication preparation and administration were identified as an error. This is strongly supported by the literature. ${ }^{10,25-28}$ Studies reveal that the main sources of interruption for nurses are other healthcare professionals, nursing staff, patients, relatives, visitors and self-interruption..$^{25} \mathrm{~A}$ recent review of the literature showed that little is known of how nurses deal with interruptions and distractions during medication administration, and points to the urge for innovative and sustainable strategies to overcome this problem. $^{28}$

Although nurses play a fundamental role in the process of medication preparation and administration, their participation was not observed in this step of the medication system, which is alarming. The nurses' responsibility in avoiding errors is highlighted since they are trained to maintain a critical and reflective approach and have scientific basis on medication administration for the patient's safety. ${ }^{29}$ It is necessary to invest to train nurses committed to patient safety in medication administration. ${ }^{10}$ Nurses need to understand that medication administration is a complex, dynamic and multifaceted phenomenon, and to be competently and responsibly involved in this process. ${ }^{1}$

It is important to analyze and organize the nursing work process in hospital institutions to optimize the quality of the service provided and to establish an institutional and professional culture of safety, promoting responsibility, non-punitive attitudes and patient safety. ${ }^{30}$

This study is limited by the cross-sectional model, which does not allow it to establish causal relations for the issues addressed. Moreover, the data analyzed is related to a delimited observational period and was limited to the employees of two public hospitals in a specific geographic territory, which can restrict the generalization of results. However, this study represents a breakthrough for the knowledge of safety in medication administration in psychiatric services, as it is the first Brazilian study, and one of the few in the world, to analyze the medication system in psychiatric admission units. 


\section{CONCLUSION}

This study analyzed the medication system of two psychiatric institutions and discussed strategies, recommendations and technological resources that can promote safety in medication systems. It was observed that organizational problems contribute towards a deficient culture of safety. Interventions and adjustments of behaviors, actions, processes, protocols and the structuring of the organization are mandatory, as patient safety is essential for the qualification of the care provided.

Health professionals, managers and researchers should consider the gaps and potentials observed in the investigated sites in order to plan and implement actions and studies that focus on psychiatric patient safety in drug therapy during their hospitalization.

\section{REFERENCES}

1. Leufer T, Cleary-Holdforth J. Let's do no harm: medication errors in nursing: Part 1. Nurse Educ Prac. 2013 May; 13(3):213-6.

2. Shahrokhi A, Ebrahimpour F, Ghodousi A. Factors effective on medication errors: a nursing view. J Res Pharm Pract. 2013 Jan-Mar; 2(1):18-23.

3. Cheragi MA, Manoocheri H, Mohammadnejad E, Ehsani SR. Types and causes of medication errors from nurse's viewpoint. Iran J Nurs Midwifery Res. 2013 May-Jun; 18(3):228-31.

4. Choi I, Lee SM, Flynn L, Kim C, Lee S, Kim NK, et al. Incidence and treatment costs attributable to medication errors in hospitalized patients. Res Soc Adm Pharm. 2016; 12(3):428-37.

5. Jayaram G, Doyle D, Steinwachs D, Samuels J. Identifying and reducing medication errors in psychiatry: creating a culture of safety through the use of an adverse event reporting mechanism. J Psychiatr Pract. 2011 Mar; 17(2):81-8.

6. Brownlie K, Schneider C, Culliford R, Fox C, Boukouvalas A, Willan C, et al. Medication reconciliation by a pharmacy technician in a mental health assessment unit. Int J Pharm Clin. 2014 Apr; 36(2):303-9.

7. Higuchi A, Higami Y, Takahama M, Yamakawa M, Makimoto K. Potential underreporting of medication errors in a psychiatric general hospital in Japan. Int J Nurs Pract. 2015; 21 (Suppl 2):2-8.

8. Cano FG, Rozenfeld S. Eventos adversos a medicamentos em hospitais: uma revisão sistemática. Cad Saúde Pública [Internet]. 2009 [cited 2014 Jan 25]; 25(Suppl 3). Available from: http://www. scielo.br/scielo.php?script=sci_arttext\&pid=S0102311X2009001500003\&lng=en
9. Soerensen AL, Lisby M, Nielsen LP, Poulsen BK, Mainz J. The medication process in a psychiatric hospital: are errors a potential threat to patient safety? Risk Manag Health Policy. 2013 Sep; 2013(6):23-31.

10. Cleary-Holdforth J, Leufer T. The strategic role of education in the prevention of medication errors in nursing: Part 2. Nurse Educ Pract. 2013 May; 13(3):21720.

11. Silva AEBC. Análise do sistema de medicação de um hospital universitário do estado de Goiás [dissertação]. Ribeirão Preto (SP): Universidade de São Paulo. Programa de Pós-Graduação em Enfermagem; 2003.

12. Oliveira RC. Análise do sistema de utilização de medicamentos em dois hospitais da cidade de RecifePE [tese]. Ribeirão Preto (SP): Universidade de São Paulo. Programa de Pós-Graduação em Enfermagem; 2005.

13. Ministério da Saúde (BR). Portaria n. 344, de 12 de maio de 1998. Aprova o regulamento técnico sobre substâncias e medicamentos sujeitos a controle especial. Diário Oficial da Republica Federativa do Brasil, 13 Fev 1999. Seção 1.

14. Peres HHC, Lima AFC, Cruz DALM, Gaidzinski RR, Oliveira NB, Ortiz DCF, et al. Avaliação de sistema eletrônico para documentação clínica de enfermagem. Acta Paul. Enferm [Internet]. 2012 [cited 2014 Nov 25]; 25(4). Available from:http://www. scielo.br/scielo.php?script=sci_arttext\&pid=S01031002012000400010\&lng=en

15. Dammenhain RA. Manual prático para prescrição de medicamentos de acordo com a legislação sanitária brasileira [manual na Internet]. 2010 [cited 2014 Oct 20]. Available from:http: www.sbrafh.org.br/site/ public/temp/5161ea3ccde67.pdf

16. Ambrosio L, Pumar-Méndez MJ. Factores del entorno de trabajo que influyen en la ocurrencia de errores de administración de medicación. Anal Sist Sanit Navar. 2013 Jan-Apr; 36(1):77-85.

17. Teixeira TCA, Cassiani SHB. Análise de causa raiz: avaliação de erros de medicação em um hospital universitário. Rev Esc Enferm USP. 2010 Mar; 44(1):139-46.

18. Franco JN, Ribeiro G, D'Innocenzo MBBP. Percepção da equipe de enfermagem sobre fatores causais de erros na administração de medicamentos. Rev Bras Enferm. 2010 Dec; 63(6):927-32.

19. Charpiat B, Goutelle S, Schoeffler M, Aubrun F, Viale JP, Ducerf C, et al. Análise de prescrições por farmacêuticos clínicos no período pós-operatório: um estudo prospectivo de quatro anos. Acta Anaesthesiol Scand. 2012 Jan; 56(8):1047-51.

20. Ministério da Saúde (BR). Portaria n. 4.283, de 30 de dezembro de 2010. Aprova as diretrizes e estratégias para organização, fortalecimento e aprimoramento das ações e serviços de farmácia no âmbito dos hospitais. Diário Oficial da República Federativa do Brasil, 31 Dez 2010. Seção 1. 
21. Ministério da Saúde (BR). Portaria n. 2.095, de, 24 de setembro de 2013. Protocolos básicos de segurança do paciente: prevenção de quedas, identificação do paciente e segurança na prescrição, uso e administração de medicamentos. Diário Oficial de República Federativa do Brasil, 25 Set 2013. Seção 1.

22. Salmasi S, Long CM, Khan TM. Interplay of medication errors and the separation of dispensing. Res Soc Adm Pharm. 2016 Jan-Feb; 12(1):171-2.

23. Coelho MS, Silva Arruda C, Faria Simões SM. Higienização das mãos como estratégia fundamental no controle de infecção hospitalar: um estudo quantitativo. Enferm Global [Internet]. 2011 [cited 2013 Dez 15]; 10(21). Available from:http://scielo. isciii.es/pdf/eg/v10n21/pt_clinica2.pdf

24. Grenard JL, Munjas BA, Adams JL, Suttorp M, Maglione M, McGlynn EA, et al. Depression and medication adherence in the treatment of chronic diseases in the United States: a meta-analysis. J Gen Intern Med. 2011 Oct; 26(10):1175-82.

25. Antoniadis S, Passauer-Baierl S, Baschnegger H, Weigl $\mathrm{M}$. Identification and interference of intraoperative distractions and interruptions in operating rooms. J Surg Res. 2014 May; 188(1):21-9.

26. Sorensen EE, Brahe L. Interruptions in clinical nursing practice. J Clin Nurs. 2014 May; 23(9-10):1274-82.

27. Monteiro C, Avelar AFM, Pedreira MLG. Interrupções de atividades de enfermeiros e a segurança do paciente: revisão integrativa da literatura. Rev LatinoAm Enfermagem. 2015 Fev; 23(1):169-79.

28. Hayes C, Jackson D, Davidson PM, Power T. Medication errors in hospitals: a literature review of disruptions to nursing practice during medication administration. J Clin Nurs. 2015 Nov; 24(21-22):3063-76.

29. Fassarella CS, Bueno AAB, Souza ECC. Segurança do paciente no ambiente hospitalar: os avanços na prevenção de eventos adversos no sistema de medicação. Rev Red Cuid Saúde. 2013 Jan-Jun; 7(1):1-8.

30. Camerini FG, Silva LD. Segurança do paciente: análise do preparo de medicação intravenosa hospitalar em hospital da rede sentinela. Texto Contexto Enferm [Internet]. 2011 [cited 2014 Nov 20]; 20(1). Available from: http:// www.scielo.br/scielo.php?script=sci arttext\&pid=S0104-07072011000100005 